\title{
Notes on the vocalizations of Mascarene White-eye (Zosterops borbonicus)
}

Peter Boesman

In the following we briefly analyze and compare voice of the two races of Mascarene Whiteeye (Zosterops borbonicus). We also try to quantify the extent of any vocal differences using the criteria proposed by Tobias et al. (2010), as a support for taxonomic review. We have made use of sound recordings available on-line from Xeno Canto (XC).

An overview of vocalizations per race, based on available recordings:

Reunion (nominate)

* a long series of variable high-pitched squeaky notes

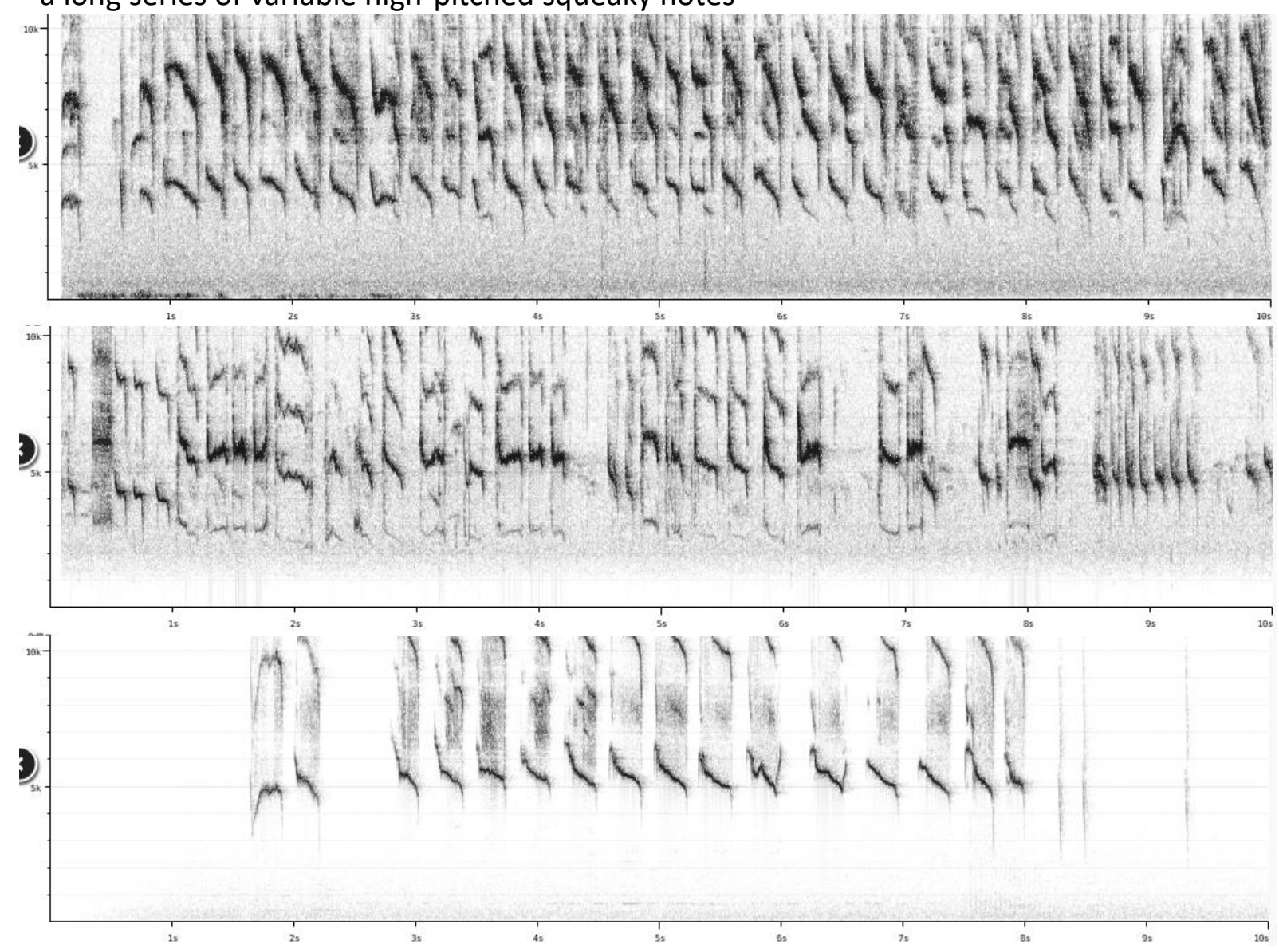


HANDBOOK OF THE

Alve

ORNITHOLOGICAL NOTES

* a somewhat more warbled short phrase at slightly lower pitch
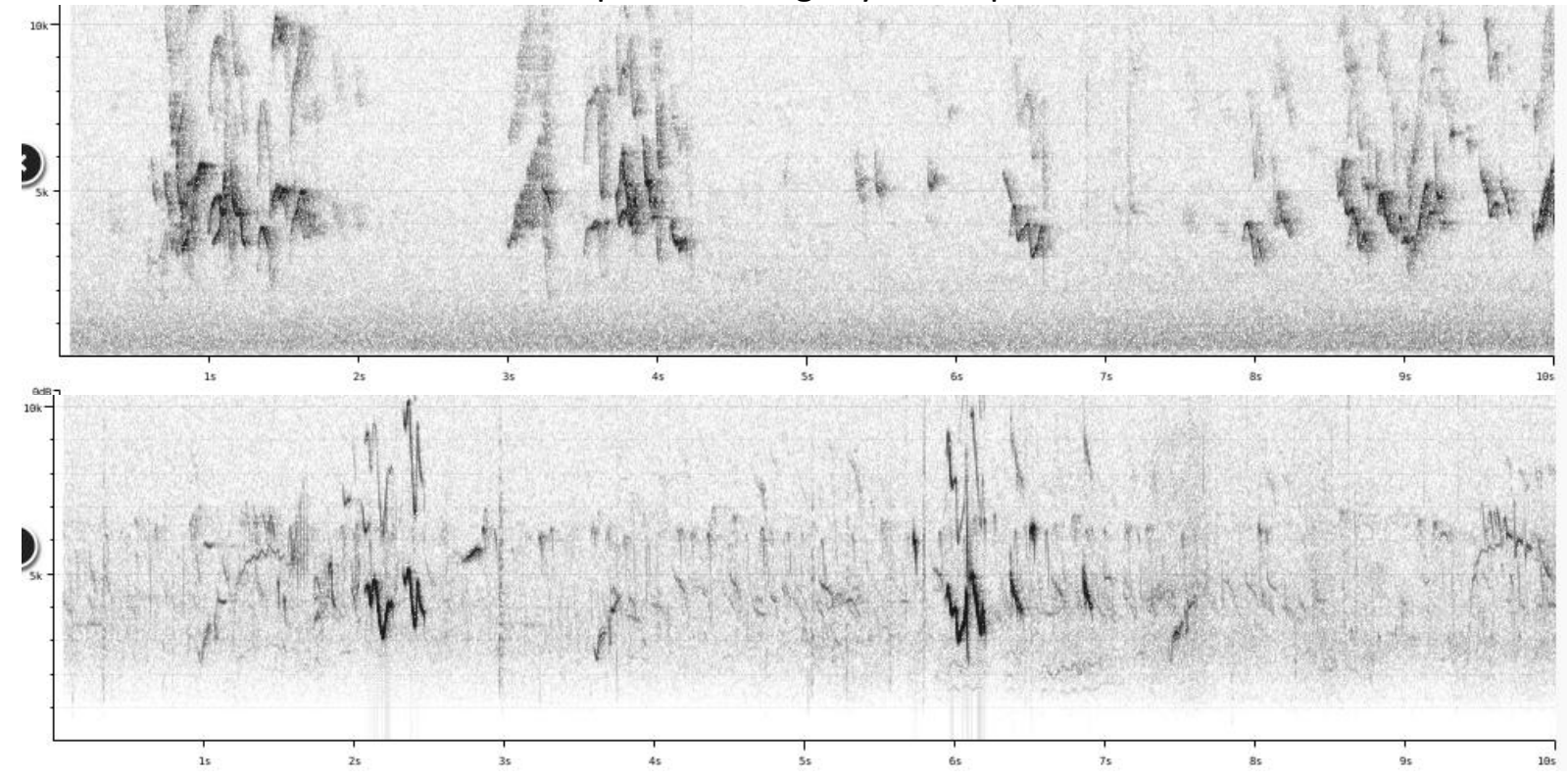

Mauritius (mauritianus)

* a sequence of downslurred chirping notes
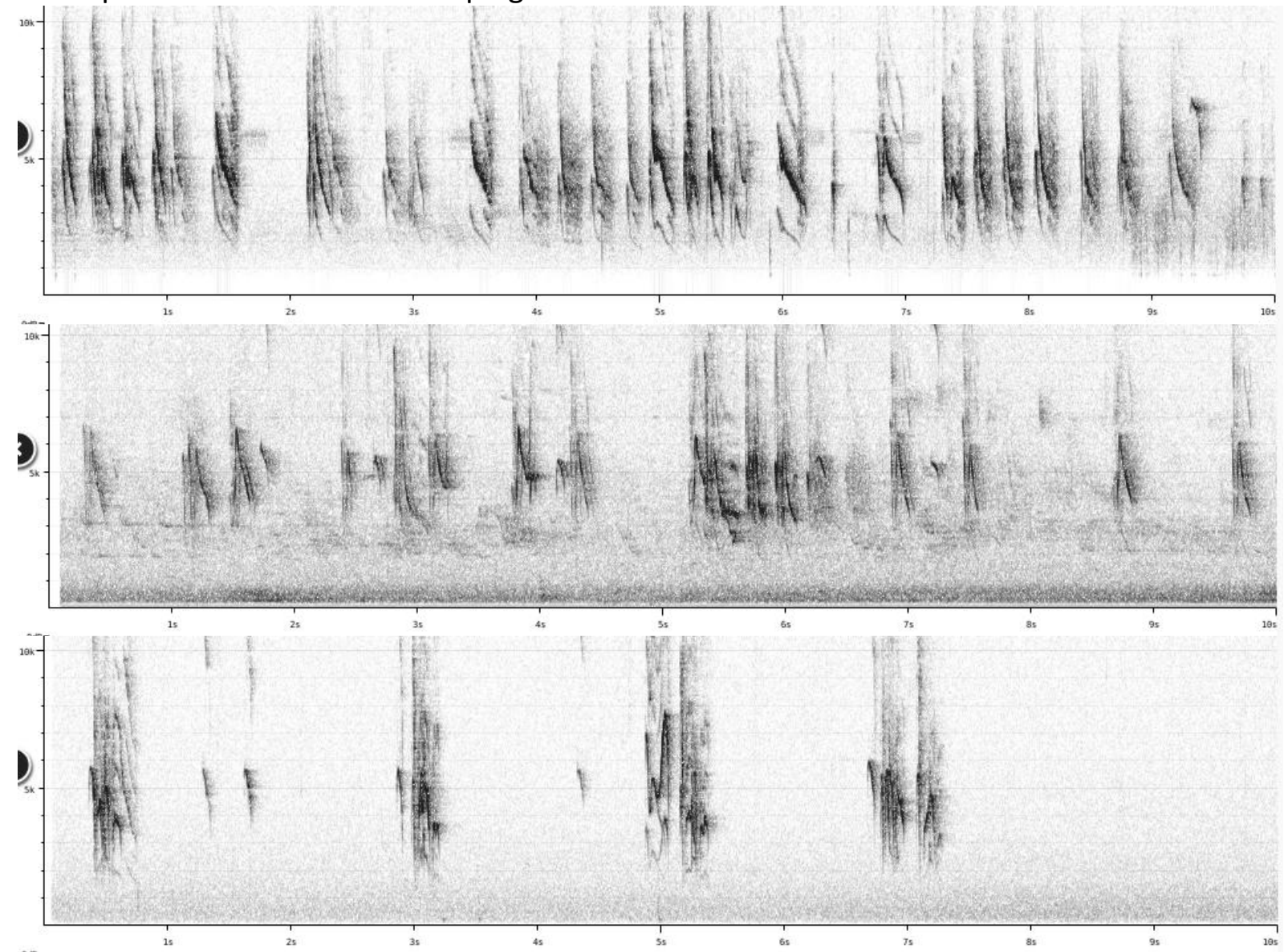

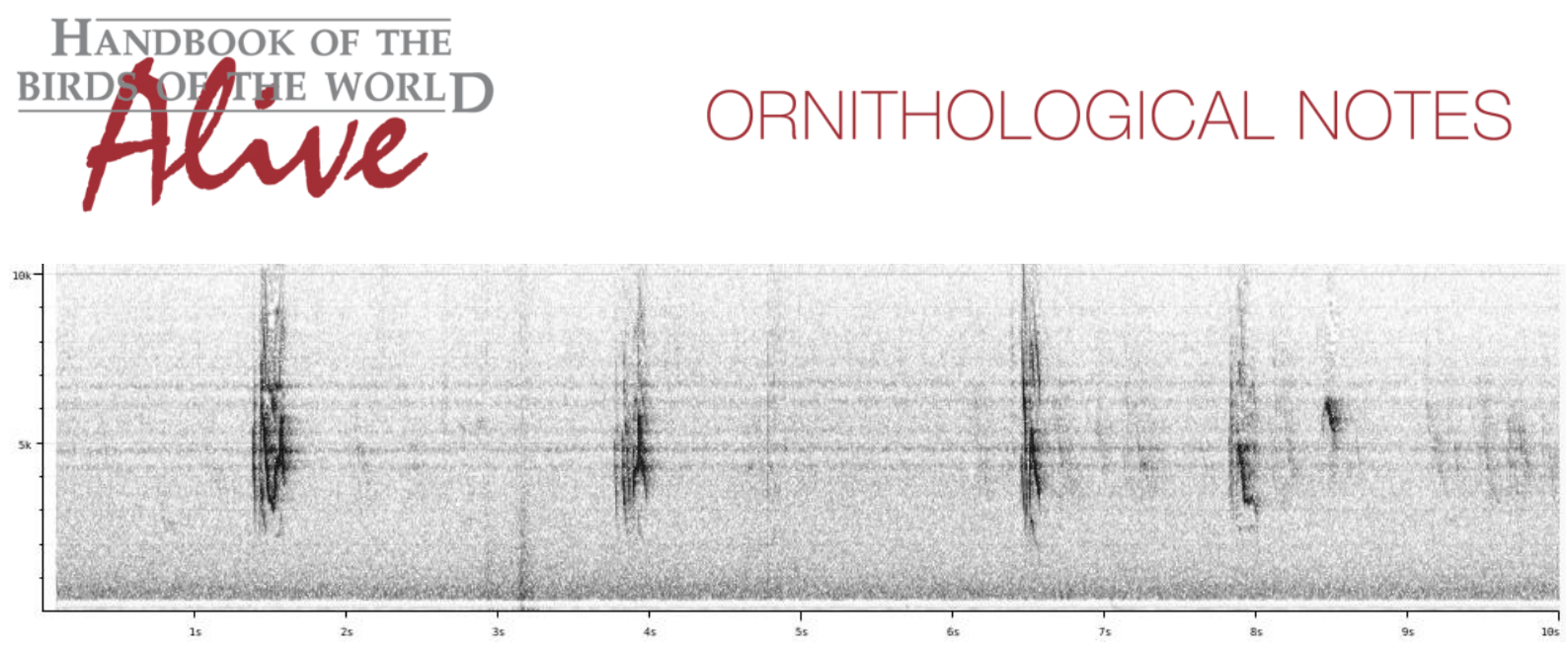

There is a clear difference in voice.

It is not $100 \%$ clear which are homologous vocalizations and which of the vocalizations can be considered territorial song, but in any case, none of the vocalizations of Mauritius are as squeaky and high-pitched as the ones commonly uttered on Reunion (score 3). The short more warbled phrases show more resemblance, and differences here are definitely more subtle. In absence of a clear set of homologous vocalizations, we estimate the total vocal score to be about 3 .

This note was finalized on 16th March 2016, using sound recordings available on-line at that moment. We would like to thank in particular the sound recordists who placed their recordings for this species on XC: Daniel Danckwerts, Phil Gregory, Frank Lambert, Dan Lane, Albert Lastukhin, Hans Matheve, Cedric Mroczko and George Sangster.

\section{References}

Tobias, J.A., Seddon, N., Spottiswoode, C.N., Pilgrim, J.D., Fishpool, L.D.C. \& Collar, N.J. (2010). Quantitative criteria for species delimitation. Ibis 152(4): 724-746.

\section{Recommended citation}

Boesman, P. (2016). Notes on the vocalizations of Mascarene White-eye (Zosterops borbonicus). HBW Alive Ornithological Note 262. In: Handbook of the Birds of the World Alive. Lynx Edicions, Barcelona. (retrieved from http://www.hbw.com/node/1251677 on 5 October 2016). 